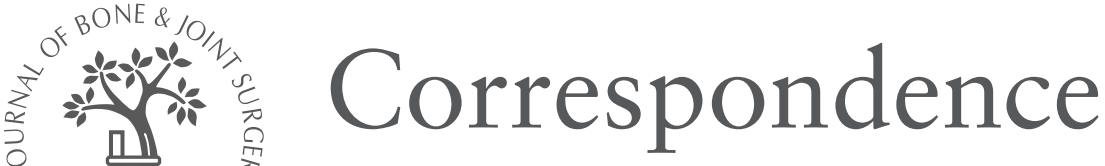

We welcome letters to the Editor concerning articles which have recently been published. Such letters will be subject to the usual stages of selection and editing; where appropriate the authors of the original article will be offered the opportunity to reply.

Letters should normally be under 300 words in length, doublespaced throughout, signed by all authors and fully referenced. The edited version will be returned for approval before publication.

(C)2005 British Editorial Society of Bone and Joint Surgery doi:10.1302/0301-620X 87B3.16168 \$2.00

$J$ Bone Joint Surg [Br] 2005;87-B:433-4.

\section{Treatment of anaemia after joint replacement}

Sir,

I read with interest the paper by Sutton et $\mathrm{al}^{1}$ in the January 2004 issue entitled 'Treatment of anaemia after joint replacement'. The treatment of anaemia after hip or knee replacement with oral iron is common, and this paper challenges the practice.

The mean level of haemoglobin at review was lower in the placebo group than in the treatment group, although this was not statistically significant. The lack of compliance may be a significant confounding factor in the analysis of the results of the study. Furthermore, most haematology laboratories accept that measurement errors of approximately $0.4 \mathrm{~g} / \mathrm{dl}$ around the reported level of haemoglobin may occur.

These factors suggest that a study with larger numbers of patients may be required to detect a rise in the values of haemoglobin after administration of oral iron. Iron deficiency anaemia is a common cause of post-operative anaemia. The dietary intake of iron may be compromised in the post-operative period due to a variety of causes including ileus, poor appetite and prolonged recovery from anaesthesia; iron therapy may be of benefit to these patients.

W. Y. KIM, MRCS

Hope Hospital,

Manchester, UK.

1. Sutton PM, Cresswell T, Livesey P, Speed K, Bagga T. Treatment of anaemia after joint replacement. J Bone Joint Surg [Br] 2004;86-B:31-3.

\section{Author's reply:}

Sir,

We thank Mr Kim for his interest in our paper. We feel it is a mistake to say that most haematology laboratories accept a measurement error of approximately $0.4 \mathrm{~g} / \mathrm{dl}$ for the level of haemoglobin. The coefficient variation for haemoglobin in the analysers used is less than $1 \%$ which would give a measurement error of approximately $0.15 \mathrm{~g} / \mathrm{dl}$.

Our paper is based on the premise that iron supplementation for anaemia after primary hip or knee replacement surgery is not beneficial unless iron deficiency has been demonstrated pre-operatively. There is a misconception that blood loss in a patient who is not iron deficient pre-operatively will cause post-operative iron deficiency. Patients who are iron replete at the time of surgery would need to lose substantial amounts of blood in order to cause iron deficiency as the amount of iron in a single unit of blood is relatively small compared with iron body stores.

We agree that the dietary intake of iron may be compromised in the post-operative period secondary to such causes as ileus, poor appetite or prolonged recovery. These conditions, however, are likely to result in a reticuloendothelial iron block in which case additional iron therapy will be of no benefit.

We would also like to reiterate that post-operative erythropoiesis is limited by the inflammatory effects of surgery on iron metabolism. This is common knowledge among haematologists but possibly less so among surgeons. Our recommendation is that patients are investigated for anaemia prior to surgery and if this is secondary to iron deficiency, treatment should be commenced preoperatively. We continue to believe that the routine administration of iron supplements to anaemic patients after hip and knee replacement is medically unsound.

P. M. SUTTON, MBCHB, FRCS(Tr \& Orth)

Northern General Hospital,

Sheffield, UK.

\section{A comparison of polyethylene wear rates between cemented and cementless cups: a prospective, randomised trial}

Sir,

We found the article by McCombe and Williams ${ }^{1}$ in the April 2004 issue entitled "A comparison of polyethylene wear rates between cemented and cementless cups" relevant to our practice.

Patients between 50 and 60 years of age are offered a hybrid hip replacement with an uncemented acetabular cup. Uncemented cups offer less flexibility than do cemented cups; we find that the centre of head rotation is frequently high and is sometimes medialised. Flanged cemented cups allow the surgeon to be more flexible with cement, particularly in those acetabula which are eroded superolaterally. As a result, the offset of the femoral component in the uncemented group can be less than pre-operative templating has indicated in order to achieve adequate soft-tissue balancing. Sakalkale et $\mathrm{al}^{2}$ have shown that increasing femoral offset reduces acetabular wear, presumably by reducing the abductor moment arm.

In a review of soft-tissue balancing of the hip by Bourne and Rorabeck ${ }^{3}$ the need to reproduce normal moment arms across the hip in the coronal plane is emphasised. Any analysis of hip mechanics should include a post-operative anteroposterior view of the pelvis so that parameters such as vertical and horizontal components of centre of head rotation, femoral offset and leg length can be estimated. Ideally, femoral neck anteversion should be included as this 
has an effect on offset. Lack of flexibility of an uncemented cup often means that the surgeon cannot antevert it and has to antevert the femoral component in order to gain stability, so reducing offset.

We would be interested in these variables in the two groups presented by the authors and draw attention to the illustration in the paper, which shows that the uncemented case has less femoral offset with a high centre of rotation. It may be that different wear rates are simply due to an increased abductor moment in the uncemented group.

\section{VANDERESTRAETEN, FRCS}

M. S. BINNS, FRCS

Pontefract General Infirmary

Pontefract, UK.

1. McCombe P, Williams SA. A comparison of polyethylene wear rates between cemented and cementless cups: a prospective, randomised trial. J Bone Joint Surg [Br] 2004;86-B:344-9.

2. Sakalkale DP, Sharkey PF, Eng K, Hozack WJ, Rothman RH. Effect of femoral component offset on polyethylene wear in total hip arthroplasty. Clin Orthop 2001;388:125-34

3. Bourne RB, Rorabeck CH. Soft-tissue balancing: the hip. J Arthroplasty 2002;17 (4 Supp 1): 17-22

\section{Author's reply:}

Sir,

We would like to thank Drs Vanderstraeten and Binns for raising their interesting points in regard to wear rates and biomechanical issues in THA. They ask if a difference in femoral offset could account for the significant difference in wear rates between cemented and cementless cups.

An Exeter stem was used in all cases. At the time of the study this stem came with a $44-\mathrm{mm}$ and a $37.5-\mathrm{mm}$ offset with the offset also increasing marginally in each group as the size of the body increased. All stem sizes and offsets were recorded. We have collated these results and found no significant difference in the spread of offsets used in the two groups. We conclude that the offset of the femoral component has not had an influence on wear in our study.

The concept of medialisation of the cup and, therefore, of the centre of rotation of the hip is a different and more complex problem. Some cups, both cemented and cementless, will end up medialised when the arthritic process is more medial. We usually try to prevent this with grafting, but in a few cases in each group there was some medialisation (Fig. 3d). This happened only occasionally in both groups and an appropriate stem was used to restore anatomical offset. We do not see this as a cause for the observed differences and would note that Wroblewski, Siney and Fleming ${ }^{1}$ has suggested that medialisation of the cup may well decrease the polyethylene wear. If medialisation of the cementless cups was thought to be a reason for a difference in wear rates, one would expect them to have less, rather than more, wear.

The most likely reason for the observed difference in wear rates between cemented and cementless cups is the difference in the elasticity. We believe the more flexible cement/polyethylene cup combination decreases the peak loads on the polyethylene helping to lessen the wear.

P. McCOMBE, FRACS

Frankston Hospital,

S. A. WILLIAMS, FRACS

Geelong Hospital,

Victoria, Australia.

1. Wroblewski BM, Siney PD, Fleming PA. Wear of the cup in the Charnley LFA in the young patient. J Bone Joint Surg [Br] 2004;86-B:498-503.

\section{Treatment of supracondylar fracture of the humerus in children by skeletal traction in a brace}

Sir,

I read with interest the article by Matsuzaki et $\mathrm{al}^{1}$ in the March 2004 issue entitled 'Treatment of supracondylar fracture of the humerus in children by skeletal traction in a brace'.

I would like to congratulate the authors on their description of an excellent method of treating a difficult and controversial fracture.

There is one aspect of the methodology that concerns me. The authors say, "We normally insert the winged screw under local anaesthetic. Before insertion we make a small hole in the olecranon using a gimlet". ${ }^{1}$ Considering the age of the patients "mean age 6.1 years (2 to 14)," I am not clear what type of local anaesthetic is used (infiltration or regional) and the level of pain experienced by the patients who have a completely displaced supracondylar humeral fracture. Surely it would be kinder to insert the screw under a short general anaesthetic?

The functional outcome is good with acceptable rates of cubitus varus and elbow stiffness. This method would be ideal in areas where image intensifiers are not readily available to permit percutaneous wiring.

I am interested in the complications of this procedure, but the authors have not mentioned infections or screw pullouts. I would be very grateful for the authors' comments regarding this.

\section{A. MICHAEL, FRCS \\ Altra Gelvin Area Hospital \\ Londonderry, UK.}

1. Matsuzaki K, Nakatani N, Harada M, Tamaki T. Treatment of supracondylar fracture of the humerus in children by skeletal traction in a brace. J Bone Joint Surg [Br] 2004;86-B:232-8

\section{Author's reply:}

Sir,

I thank Mr Michael for his interest in our paper, and I will try to clarify the points he mentions.

In cases of patients who are four years old or younger, general anaesthesia is often necessary to insert the screw. I agree that it is kinder to use general anaesthesia in young children with a fracture.

We have used general anaesthesia in 35 children $(18 \%)$ with this fracture: 13 girls and 18 boys of four years old or less, and four children between four and six years old. In 158 children we inserted the winged screw under local anaesthesia. Which procedure is preferable is still under discussion. We usually insert the screw within ten minutes. Supracondylar fracture of the humerus can be managed quickly by our method with local anaesthesia, usually lidocaine (1\%).

We did have some complications with the winged traction screw. Approximately 30\% of the cases had screws that loosened, but there were no pullouts. We managed to apply continuous traction in a brace, usually with a force of $2.3 \mathrm{~kg}$, despite the loosened screws, because the applied force is not great.

We had some superficial infections around the screw, with a purulent discharge in approximately $20 \%$ of the cases. We continued the traction because the inflammatory signs were localised and all the wounds healed within a week after the screw was removed and there were no cases of osteomyelitis of the ulna. In no case was it necessary to remove the screw due to deep infection.

K. MATSUZAKI. MD

Wakayama Medical University

Kimiidera, Japan. 